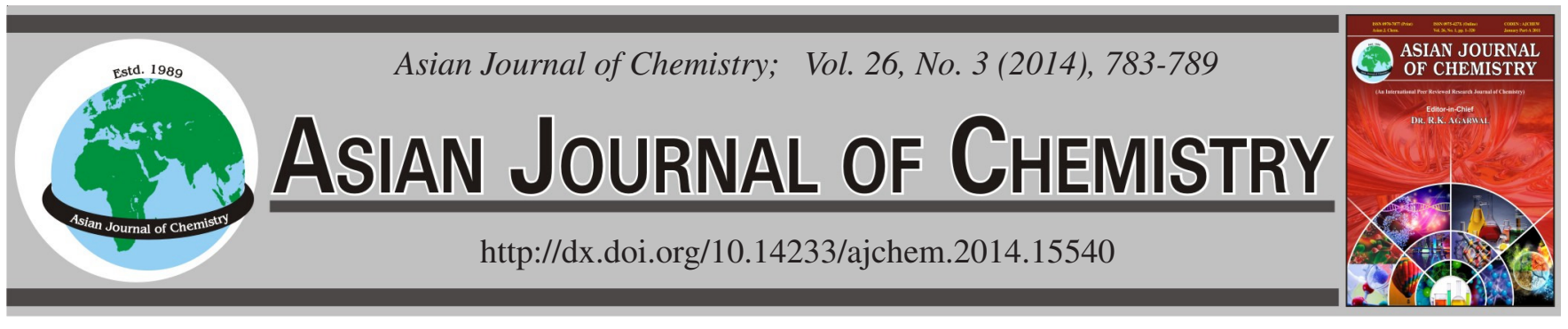

\title{
Synthesis and Studies on Electroactive Poly(3-chloroaniline), Poly(3-chloroaniline)- Blend-polyethyleneglycol and Poly(3-chloroaniline)-Blend-Poly(vinyl alcohol)
}

\author{
L. Porselvi and S. Jhancy MARY*
}

PG and Research Department of Chemistry, Auxilium College, Vellore-632 006, India

*Corresponding author: Fax: +91 4162 2247281; E-mail: jhancy2011@gmail.com

\begin{abstract}
The poly(3-chloroaniline), poly(3-chloroaniline)-blend-polyethyleneglycol and poly(3-chloroaniline)-blend-poly(vinyl alcohol) were prepared by in situ oxidative polymerization technique using ammonium per sulphate as oxidizing agent and $\mathrm{HCl}$ as dopant. The polymer and its blends were characterized by FT-IR, UV-visible spectroscopy, thermogravimetric analysis and electrical conductivity. The synthesized polymer and its blends show the presence of benzenoid structure, quinonoid structure and the formation of the charged species $\left(\mathrm{Q}=\mathrm{N}^{+}\right.$ $\mathrm{H}-\mathrm{B}$ or $\left.\mathrm{B}-\mathrm{N}^{+} \mathrm{H}-\mathrm{B}\right)$. Absorption band appear in the range 450-550 $\mathrm{nm}$ in polyaniline, whereas in the poly(3-chloroaniline) and its blends it is shifted to lower wave length because of the electronic effect which has reduced the amount of delocalization there by increasing the energy gap. The complex impedance of the polymer and its blends were measured by using four point probe method. The electrical conductivities of poly(3-chloroaniline), poly(3-chloroaniline)-blend-polyethyleneglycol and poly(3-chloroaniline)-blend-poly(vinyl alcohol) were $1.37 \times 10^{-11} \mathrm{~S} \mathrm{~cm}^{-1}, 3.67 \times 10^{-11} \mathrm{~S} \mathrm{~cm}^{-1}$ and $2.64 \times 10^{-9} \mathrm{~S} \mathrm{~cm}^{-1}$ respectively. The blends synthesized were of semiconducting nature and poly(3-chloroaniline)-blend-poly(vinyl alcohol) has higher conductivity than poly(3-chloroaniline) and poly(3-chloroaniline)-blendpolyethyleneglycol.
\end{abstract}

Keywords: Poly(3-chloroaniline), Poly(vinyl alcohol), Polyethyleneglycol, Four point probe method, Complex impedence.

\section{INTRODUCTION}

Electrically conducting polymers have raised a great deal of interest after the successful synthesis of conducting polyacetylenes by Shirakawa et al. ${ }^{1}$. Conducting polymers also known as synthetic metals are polymers with a highly $\pi$-conjugated polymeric chain ${ }^{2-4}$. Typically conducting polymers include polyacetylene, polyaniline, polypyrrole, polythiophene, poly(para-phenylene), polyphenylenevinylene, polyfuran, etc. These conjugated polymers can be electrical insulators, semiconductors or conductors, depending on the level of doping and nature of the dopants.

Among these conductive polymers, polyaniline has special advantages, such as ease of synthesis, environmental stability, low cost of the monomer, nonredox doping by protonic acids and ready modification of the oxidation states of the polymer chain ${ }^{5}$. The applications of polyaniline in various important fields include active electrode ${ }^{6,7}$, electromagnetic shielding materials, microelectronic materials and electrochromic device, metal anti-corrosive coating ${ }^{8,9}$, anti-static coating $^{10}$, rechargeable batteries ${ }^{11,12}$, energy storage and transfer, redox micro-template ${ }^{13}$, indicators and sensors ${ }^{14,15}$. The conducting polyaniline microparticles can be electrostatically accelerated to hypervelocities, indicating their suitability as mimics of solar system dusts for the calibration of impact ionization detectors for space $\mathrm{craft}^{16}$. Polyaniline also shows high gas-separation ability with the highest ideal oxygen/ nitrogen separation factor of up to $30^{17}$.

However, the applications of polyaniline have been limited by its intractable nature as it is usually obtained chemically as an insoluble powder and electrochemically as a thin brittle film $^{18}$. Considerable progress has been made in the last few years in the processibility of conducting polymers by the synthesis of polymer blends and composites ${ }^{19,20}$ and soluble polyaniline derivatives and copolymers ${ }^{21,22}$. The processability and solubility of polyaniline were improved by using various groups at the ring or $\mathrm{N}$-substituents. Electron donating groups such as alkyl, alkoxy and amino, or electron withdrawing groups such as carboxyl, sulpho and cyano decrease orbital overlap of the $\pi$-electrons and the nitrogen lone pair that may increase the solubility and readiness for processability. However, they have been found to be more or less conducting than polyaniline depending on the nature of the blending materials, even though they are more soluble ${ }^{23}$.

The synthesis of different homopolymers and copolymers derived from anilines with electron with drawing groups has 
been reported. Ranger and Leclrc ${ }^{24}$ synthesized poly (cyanoanilines) and poly(cyanoaniline-co-aniline) by chemical methods. Yu et al..$^{25}$ reported the chemical copolymerizations of aniline with mono-ortho-halogenated anilines (2-chloroaniline and 2-iodoaniline). The synthesis of poly(aniline-co-2-chloroaniline)- $p$-toluene-sulfonate and poly(aniline-co-2-chloroaniline) formate salts by chemical polymerization has been reported by Palaniappan ${ }^{26}$. A few studies on the oxidative polymerization of mono- and di-substituted anilines with electron with drawing groups have been reported ${ }^{25,27}$.

An attempt has been made to chemically synthesize 3-chloro substituted polyaniline and its blends using in situ oxidative polymerization technique and to study their thermal and electrical properties. A study on the effect of the substituent on the rate of polymerization, thermal stability and electrical conductivity may also be made. The attempt to synthesize blends of poly(3-chloroaniline) could open up avenues in the field of research in conducting polymers with interesting commercial applications.

\section{EXPERIMENTAL}

Poly(3-chloroaniline) and its blends were chemically synthesized in aqueous acidic medium using ammonium per sulphate $\left(\mathrm{NH}_{4}\right)_{2} \mathrm{~S}_{2} \mathrm{O}_{8}$ as the oxidizing agent using modifications in the method already reported in the literature ${ }^{28}$.

Polymerization of 3-chloroaniline (monomer: oxidant = 1:1): $10.9 \mathrm{~mL}$ of 3-chloroaniline $(0.0858 \mathrm{~mol})$ was mixed with $50 \mathrm{~mL}$ of water in the reaction vessel. $19.6 \mathrm{~g}$ of ammonium persulphate $(0.0858 \mathrm{~mol})$ was dissolved in $50 \mathrm{~mL}$ water. $20 \mathrm{~mL}$ of concentrated hydrochloric acid was taken separately in a $100 \mathrm{~mL}$ beaker. The reaction vessel containing 3-chloroaniline was placed in the freezing mixture. Added the oxidant and acid alternatively in drops with constant stirring using the magnetic stirrer over a period of $2 \mathrm{~h}$. After the addition was over, the stirring was continued for $3 \mathrm{~h}$. The product formed was kept in the refrigerator overnight and then filtered. The solid product formed was again transferred into a $250 \mathrm{~mL}$ beaker, suspended in water and stirred for $1 \mathrm{~h}$ on a magnetic stirrer, washed several times with water and filtered. The washing of the product was continued till the filtrate was free of acid. The pale brown product formed was dried and finely powdered. The synthesis using the monomer oxidant ratio 1:1 resulted in low yield.

Polymerization of 3-chloro aniline (monomer: oxidant = 1:2): $5.45 \mathrm{~mL}$ of 3-chloro aniline $(0.0427 \mathrm{~mol})$ was mixed with $25 \mathrm{~mL}$ of water in the reaction vessel. $19.6 \mathrm{~g}$ of ammonium persulphate $(0.0858 \mathrm{~mol})$ was dissolved in $50 \mathrm{~mL}$ water. $20 \mathrm{~mL}$ of concentrated hydrochloric acid was taken separately in a $100 \mathrm{~mL}$ beaker. The reaction vessel containing 3-chloro aniline was placed in the freezing mixture. The oxidant and the acid were also kept in the freezing mixture. Added the oxidant and acid alternatively in drops with constant stirring using the magnetic stirrer over a period of $2 \mathrm{~h}$. After the addition was over, the stirring was continued for $3 \mathrm{~h}$. The product formed was kept in the refrigerator overnight and then filtered.

The product formed was again transferred into a $250 \mathrm{~mL}$ beaker, suspended in water and stirred for $1 \mathrm{~h}$ on a magnetic stirrer, washed several times with water and filtered. The washing of the product was continued till the filtrate was free of acid. The product formed was dried and finely powdered. A dark grey solid was obtained. The yield of the product was $3 \mathrm{~g}$.

The synthesis of the polymer when the monomer: oxidant ratio 1:1 was not successful as confirmed by FTIR spectral studies. Only the synthesis when the monomer: oxidant ratio was $1: 2$ resulted in polymerization. Hence the poly(3-chloro aniline)-blend-polyethyleneglycol and poly(3-chloroaniline)blend-poly(vinyl alcohol) were also synthesized by using the monomer: oxidant ratio as 1:2.

Synthesis of poly(3-chloroaniline)-blend-polyethy leneglycol and poly(3-chloroaniline)-blend-poly(vinyl alcohol): The method adopted was polymerization of a monomer in a polymer matrix. $5 \mathrm{~g}$ of polyethyleneglycol/ poly(vinyl alcohol) was dissolved in $100 \mathrm{~mL}$ of water and added $50 \mathrm{~mL}$ of concentrated hydrochloric acid in the reaction vessel. 3-Chloroaniline $(5.5 \mathrm{~mL})$ was mixed with $7.2 \mathrm{~mL}$ of concentrated hydrochloric acid and $25 \mathrm{~mL}$ of water. $19.6 \mathrm{~g}$ of ammonium persulphate was dissolved in $46 \mathrm{~mL}$ of water. The beaker containing polyethyleneglycol/poly(vinyl alcohol) in concentrated hydrochloric acid was kept in the freezing mixture. The monomer suspended in water, hydrochloric acid and the oxidant solution were added drop wise to it with constant stirring over a period of $1.5 \mathrm{~h}$.

The stirring was continued for $3 \mathrm{~h}$. The product was placed in the refrigerator overnight and filtered. The blend was again transferred into a $250 \mathrm{~mL}$ beaker, suspended in water and stirred for $1 \mathrm{~h}$ on a magnetic stirrer, washed with water and filtered. The washing of the products were continued till the filtrates were free of acid. The products formed were dried and powdered. The poly(3-chloroaniline), poly(3-chloroaniline)-blend-polyethyleneglycol and poly(3-chloroaniline)blend-poly(vinyl alcohol) were dark grey, dark blue and dark green respectively and they were soluble in DMSO and DMF.

In the present investigation, transmittance spectra were used to quantify the characteristic peaks of the polymer and its blends in the mid infrared region between 4000 to $400 \mathrm{~cm}^{-1}$ with $0.5 \mathrm{~cm}^{-1}$ resolution, using Thermo Nicolet-Model:Magna 550. The UV-visible spectra of the polymer and its blends in DMSO were recorded from 200-800 nm wavelength using a Systronics double beam UV-visible spectrophotometer 2201. The thermo gravimetric analysis of the poly(3-chloroaniline) and its blends were carried out in a Q50 V20.6 Build 31 thermal analyzer from $27{ }^{\circ} \mathrm{C}$ to $700{ }^{\circ} \mathrm{C}$ at a heating rate of $15^{\circ} \mathrm{C} \mathrm{min}{ }^{-1}$ under nitrogen atmosphere with gas flow rate of $90 \mathrm{~mL} \mathrm{~min}^{-1}$.

The complex impedance measurements were carried out on pelleted specimens of poly(3-chloroaniline) and its blends using a Hewlett Packard model HP4284A precision LCR meter in the frequency range $20 \mathrm{HZ}-1 \mathrm{MHZ}$ and in the temperature range $295-445 \mathrm{~K}$. Accordingly, the synthesized solid polymer and its blends were ground into fine powders and disc shaped pellets of $13 \mathrm{~mm}$ diameter and the required thickness were prepared by pressing the powder samples in an IR sample press under a pelletizing pressure of $7 \mathrm{ton} / \mathrm{cm}^{2}$ to form circular pellets. The thicknesses of the pellets were measured using a screw gauge. 


\section{RESULTS AND DISCUSSION}

The FTIR spectrum of poly(3-chloroaniline) as in Fig. 1 shows the presence of both benzenoid and quinonoid rings. A strong peak at $1585 \mathrm{~cm}^{-1}$ confirms the presence of quinonoid ring and that at $1508 \mathrm{~cm}^{-1}$ is characteristic of a benzenoid structure $^{29,30}$. N- H stretching frequencies are observed at 3392 $\mathrm{cm}^{-1}$ in the polymer and a doublet at $3500 \mathrm{~cm}^{-1}$ in the monomer. A comparison of the spectra with the IR spectrum of the monomer indicates an increase in symmetry. The stretching and bending frequencies are tabulated in Table- 1 and assignments have been made based on literature. According to studies made by Tang et al. ${ }^{29}$, the presence of a band around 1145 $\mathrm{cm}^{-1}$ can be related to the vibrational mode of protonated amines generated during the acid doping process. This peak appears around $1145 \mathrm{~cm}^{-1}$ in the FTIR spectrum of poly(3chloroaniline) due to $\left(\mathrm{Q}=\mathrm{N}^{+} \mathrm{H}-\mathrm{B}\right.$ or $\left.\mathrm{B}-\mathrm{N}^{+} \mathrm{H}-\mathrm{B}\right)$. The band at $1164 \mathrm{~cm}^{-1}$ corresponds to the bending of $\mathrm{C}-\mathrm{H}$ in plane mode of $\mathrm{N}=\mathrm{Q}=\mathrm{N}$ as reported. The $\mathrm{C}-\mathrm{Cl}$ stretching frequency is observed around $792 \mathrm{~cm}^{-1}$.

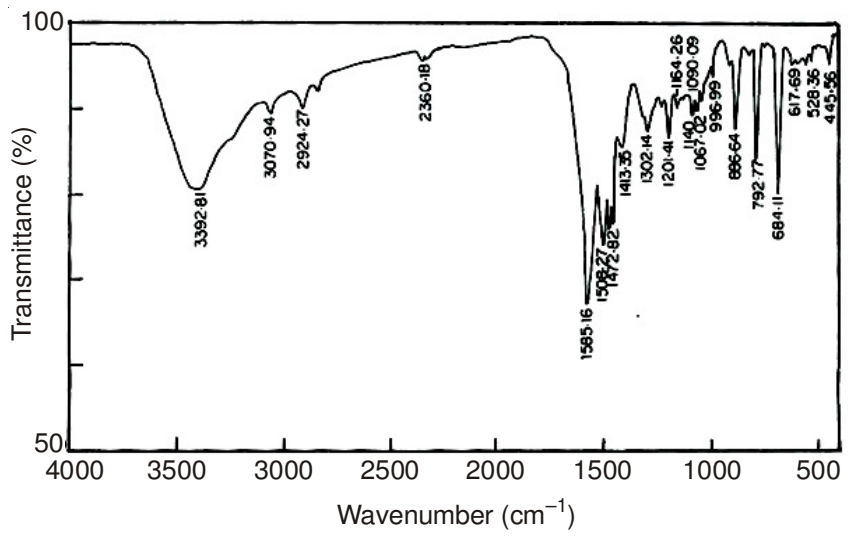

Fig. 1. FTIR spectrum of poly(3-chloroaniline)

\begin{tabular}{|c|c|}
\hline \multicolumn{2}{|c|}{$\begin{array}{l}\text { TABLE-1 } \\
\text { ASSIGNMENTS OF THE MAIN PEAKS IN THE FTIR SPECTRUM } \\
\text { OF POLY(3-CHLOROANILINE) }\end{array}$} \\
\hline Peak assignment & Wave number $\left(\mathrm{cm}^{-1}\right)$ \\
\hline N- H Stretching vibration & 3392 \\
\hline C- H Stretching vibration of aromatic ring & 3070 \\
\hline$-\mathrm{C}=\mathrm{C}-$ stretching of quinonoid & 1585 \\
\hline$-\mathrm{C}=\mathrm{C}-$ stretching of benzenoid & 1508 \\
\hline Stretching of $\mathrm{C}-\mathrm{N}$ aromatic & 1302 \\
\hline Bending of $-\mathrm{C}-\mathrm{H}$ in plane mode of $\mathrm{N}=\mathrm{Q}=\mathrm{N}$ & 1164 \\
\hline C- $\mathrm{Cl}$ stretching vibration & 792 \\
\hline $\mathrm{B}-\mathrm{N}^{+} \mathrm{H}-\mathrm{B} / \mathrm{Q}=\mathrm{N}^{+} \mathrm{H}-\mathrm{B}$ & 1140 \\
\hline Structure of $\mathrm{N}=\mathrm{Q}=\mathrm{N}$ & 1201 \\
\hline
\end{tabular}

Analogues to the studies made on polyaniline and based on the interpretation of the FTIR data, the following reaction has been proposed.

Fig. 2. shows the absorption spectrum of poly(3-chloroaniline). The spectrum of 3-chloroaniline in DMF exhibits a band at $216 \mathrm{~nm}$. In poly(3-chloroaniline) it is shifted to a higher wavelength of $246 \mathrm{~nm}$. An absorption band at $246 \mathrm{~nm}$ is due to the $\pi-\pi^{*}$ transition of the benzenoid and quinonoid rings. The bathochromic shift indicates an increase in the extent of delocalization. In the case of polyaniline, absorption bands
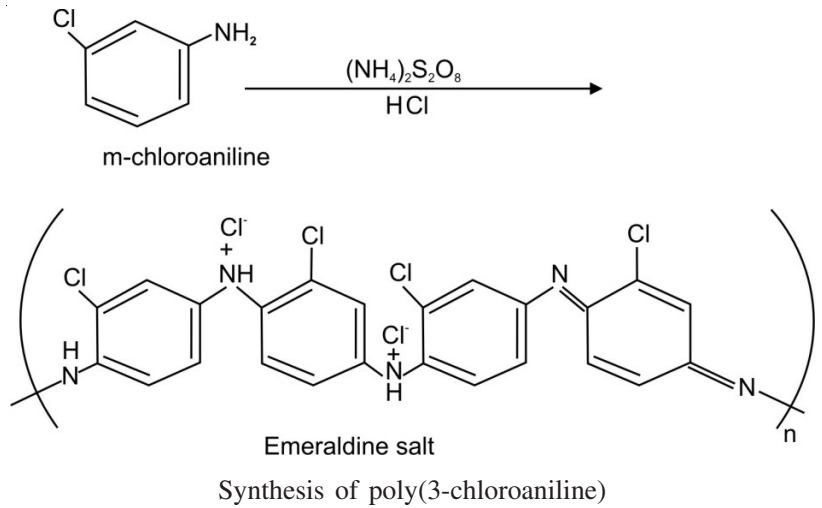

appear in the range $450-550 \mathrm{~nm}$, which is the characteristic absorption spectrum of the salt form of polyaniline ${ }^{31-33} \cdot \pi$-Electrons move from one ring to another and the $\pi$-electron delocalization takes place over the entire molecule. The greater the amount of delocalization, the smaller the energy gap between the $\pi$-orbitals. In the case of poly(3-chloroaniline), the steric factor and the electronic effect reduce the amount of delocalization there by increasing the energy gap and so the transition occurs at lower wavelength, lower than poly aniline. The substituent in the meta position to the amino group reduces the electron density to a greater extent. The weak absorption at $502 \mathrm{~nm}$ is due to $\mathrm{n}-\pi^{*}$ transition.

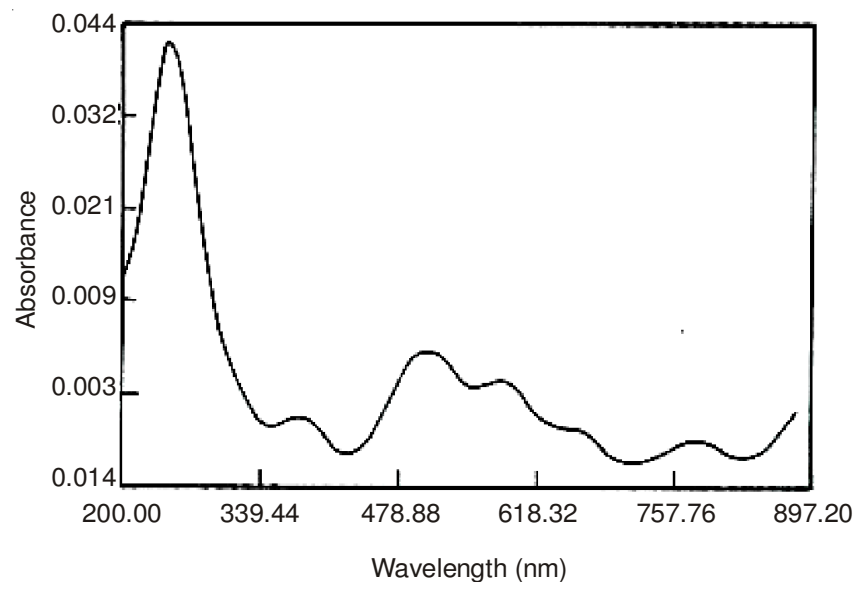

Fig. 2. UV-visible spectrum of poly(3-chloroaniline)

DTA-TGA of poly(3-chloroaniline) is given in Fig. 3. The decomposition of the polymer occurs prominently and exothermally at a peak temperature of $261{ }^{\circ} \mathrm{C}$. Water is lost at $100{ }^{\circ} \mathrm{C}$ which is immediately followed by the exothermic decomposition of the polymer. It is seen that the exothermicity is high as evidenced by a broad peak. This might have compensated the loss of water. At this temperature the weight loss is about $60.75 \%$. It is also noted that even after $600{ }^{\circ} \mathrm{C}$, complete decomposition has not taken place. The presence of chlorine atom has prevented the complete decomposition of the pure polymer.

The FTIR spectrum of poly(3-chloroaniline)-blendpolyethyleneglycol is shown in Fig. 4. Assignments of the main peaks in the FTIR spectrum of the blend are presented in Table-2. The N-H stretching frequency appears at $3408 \mathrm{~cm}^{-1}$. 


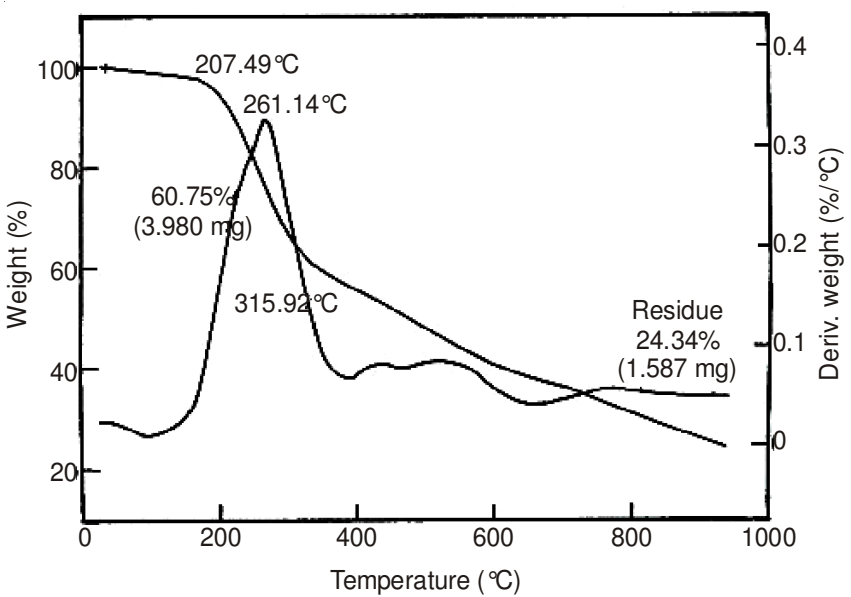

Fig. 3. DTA / TGA of poly(3-chloroaniline)

Since it is a singlet it shows that $m$-chloro aniline has undergone polymerization and there is no free $\mathrm{NH}_{2}$ group. The peak at $1596 \mathrm{~cm}^{-1}$ is due to the quinonoid ring and the peak at 1378 $\mathrm{cm}^{-1}$ is due to the benzenoid ring ${ }^{29,30}$ structure. The $\mathrm{C}-\mathrm{Cl}$ band occurs at $778 \mathrm{~cm}^{-1}$. The $\mathrm{OH}$ band appears at $3829 \mathrm{~cm}^{-1}$. Since the IR spectrum contains all the main bands of poly(3chloroaniline) and polyethyleneglycol, it shows that blending has taken place. The peak at $1114 \mathrm{~cm}^{-1}$ is due to the emeraldine salt structure which contributes to the electrical conductivity of the blend as reported by Tang et al. ${ }^{29}$. The intensity of the bands has decreased which indicates that the polymerization has taken place.

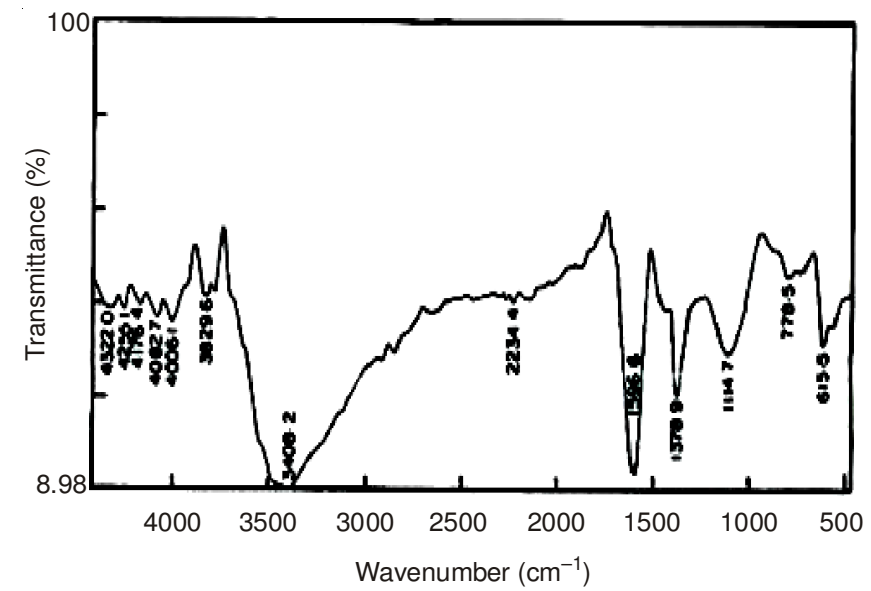

Fig. 4. FTIR spectrum of poly(3-chloroaniline)-blend-polyethylene glycol

TABLE-2

ASSIGNMENTS OF THE MAIN PEAKS IN THE FTIR SPECTRUM OF POLY(3-CHLOROANILINE)-BLEND POLYETHYLENEGLYCOL

\begin{tabular}{lc}
\hline Peak assignment & Wave number $\left(\mathrm{cm}^{-1}\right)$ \\
\hline N-H stretching frequency & 3408 \\
$-\mathrm{C}=\mathrm{C}-$ stretching of quinonoid / & 1596 \\
N-H bending vibration & 1378 \\
$-\mathrm{C}=\mathrm{C}-$ stretching of benzenoid & 1114 \\
$\mathrm{~B}-\mathrm{N}^{+} \mathrm{H}-\mathrm{B} / \mathrm{Q}=\mathrm{N}^{+} \mathrm{H}-\mathrm{B}$ & 778 \\
$-\mathrm{C}-\mathrm{Cl}$ stretching vibration & 3829 \\
$-\mathrm{CH}-\mathrm{OH}$ polyvalent alcohols & \\
\hline
\end{tabular}

Fig. 5. shows the optical absorption spectrum of poly(3chloroaniline)-blend-polyethyleneglycol. The spectrum of the blend in DMSO exhibits band at $225 \mathrm{~nm}$ and $293 \mathrm{~nm}$. The absorption band at $225 \mathrm{~nm}$ is due to $\pi-\pi^{*}$ transition of the benzenoid and quinonoid rings and the band $293 \mathrm{~nm}$ is due to $\mathrm{n}-\pi^{*}$ transition. It occurs at longer wavelength. When compared to polyaniline, it is shifted to lower wavelength because of the electronic effect which has reduced the amount of delocalization there by increasing the energy gap.

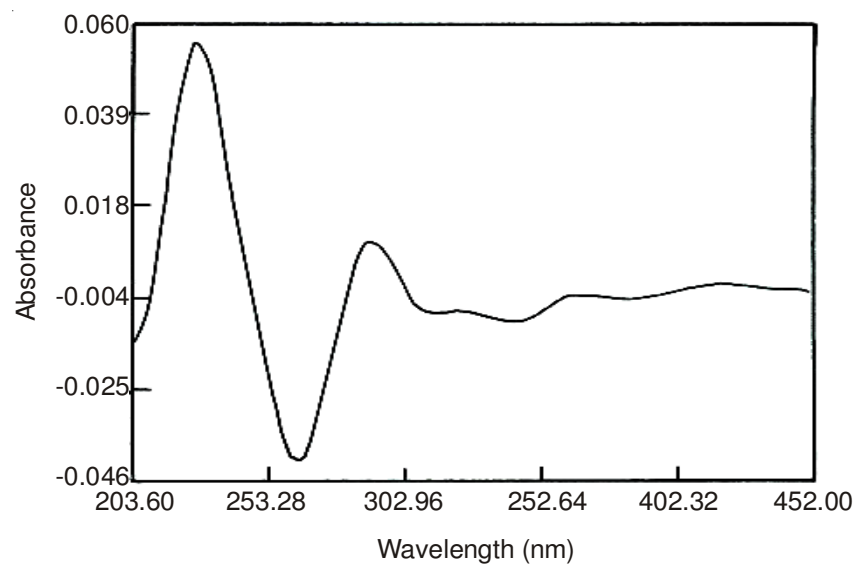

Fig. 5. UV-visible spectrum of poly(3-chloroaniline)-blend-poly ethyleneglycol

The TGA of the blend of poly(3-chloroaniline)-blendpolyethyleneglycol is given in Fig. 6. The sample decomposes in two steps. Initially there is loss of water and there is loss of the $\mathrm{HCl}$ at $249^{\circ} \mathrm{C}$. Then the decomposition of the polymer is continuous upto $692{ }^{\circ} \mathrm{C}$ and even after $690{ }^{\circ} \mathrm{C}$ the complete decomposition has not taken place. The decomposition of the blend leaves a char content of $21.54 \%$. This shows that the presence of chlorine has prevented the complete decomposition of the blend.

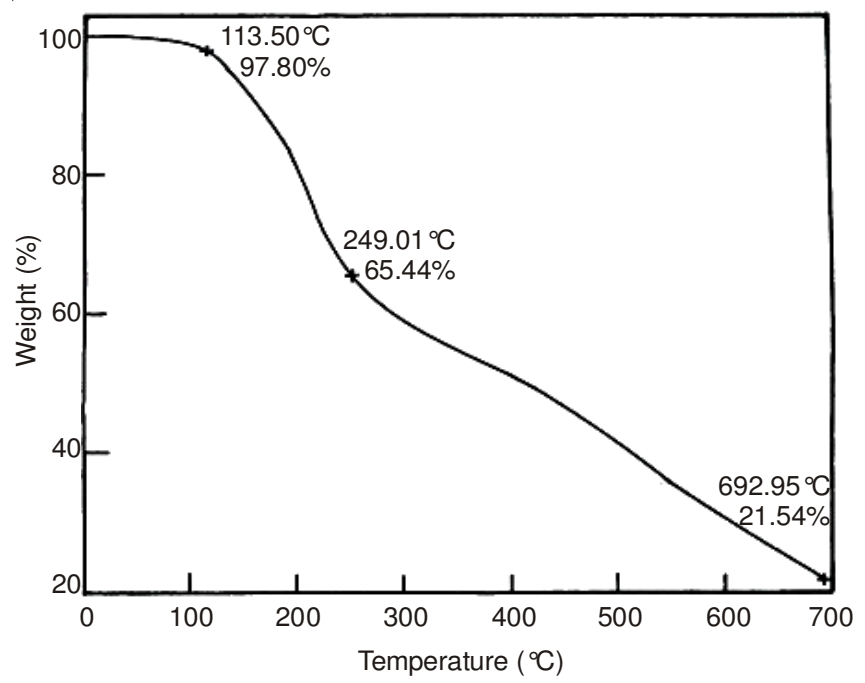

Fig. 6. TGA of poly(3-chloroaniline)-blend-polyethyleneglycol

The FTIR spectrum of poly(3-chloroaniline)-blendpoly(vinyl alcohol) is shown in Fig. 7. Assignments of the main peaks in the FTIR spectrum of the blend are presented in Table-3. The N-H stretching frequency appears at $3399 \mathrm{~cm}^{-1}$. Since it 
is singlet it shows that 3-chloroaniline has undergone polymerization and there is no free $\mathrm{NH}_{2}$ group. The peak at $1596 \mathrm{~cm}^{-1}$ is due to the quinonoid ring and the peak at 1381 $\mathrm{cm}^{-1}$ is due to the benzenoid ring $\mathrm{g}^{29,30}$ structure. The $-\mathrm{C}-\mathrm{Cl}$ band occurs at $769 \mathrm{~cm}^{-1}$. The $-\mathrm{OH}$ bands appear at $3786 \mathrm{~cm}^{-1}$. Since the IR spectrum contains all the main bands of poly(3chloroaniline) and poly(vinyl alcohol), it shows that blending taken place. The peak at $1124 \mathrm{~cm}^{-1}$ is due to the emeraldine salt structure which contributes to the electrical conductivity of the blend as reported by Tang et al. ${ }^{29}$. The intensity of the bands has decreased which indicates that the polymerization has taken place.

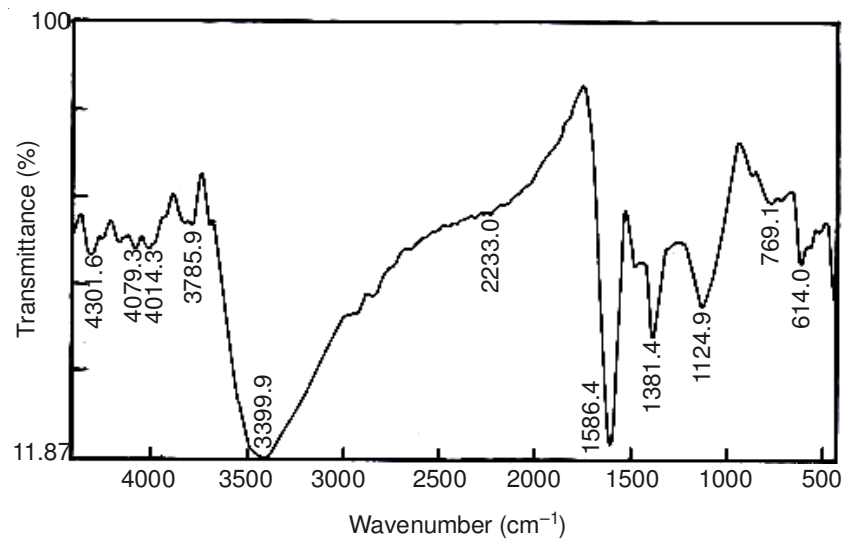

Fig. 7. FTIR spectrum of poly(3-chloroaniline)-blend-poly(vinyl alcohol)

\begin{tabular}{lc}
\multicolumn{2}{c}{ TABLE-3 } \\
ASSIGNMENTS OF THE MAIN PEAKS IN THE FTIR SPECTRUM \\
OF POLY(3-CHLOROANILINE)-BLEND-POLYVINYLALCOHOL \\
\hline Peak assignment & Wavenumber $\left(\mathrm{cm}^{-1}\right)$ \\
\hline N-H stretching vibration & 3399 \\
-C=C- stretching of quinonoid / & 1596 \\
N-H bending vibration & 1381 \\
-C $=\mathrm{C}-$ stretching of benzenoid & 1124 \\
B-N ${ }^{+} \mathrm{H}-\mathrm{B} / \mathrm{Q}=\mathrm{N}^{+} \mathrm{H}-\mathrm{B}$ & 769 \\
$-\mathrm{C}-\mathrm{Cl}$ stretching vibration & 3786 \\
$-\mathrm{CH}-\mathrm{OH}$ (polyvalent alcohols) & \\
\hline
\end{tabular}

Fig. 8 shows the optical absorption spectrum of poly(3chloroaniline) with poly(vinyl alcohol). The spectrum of the

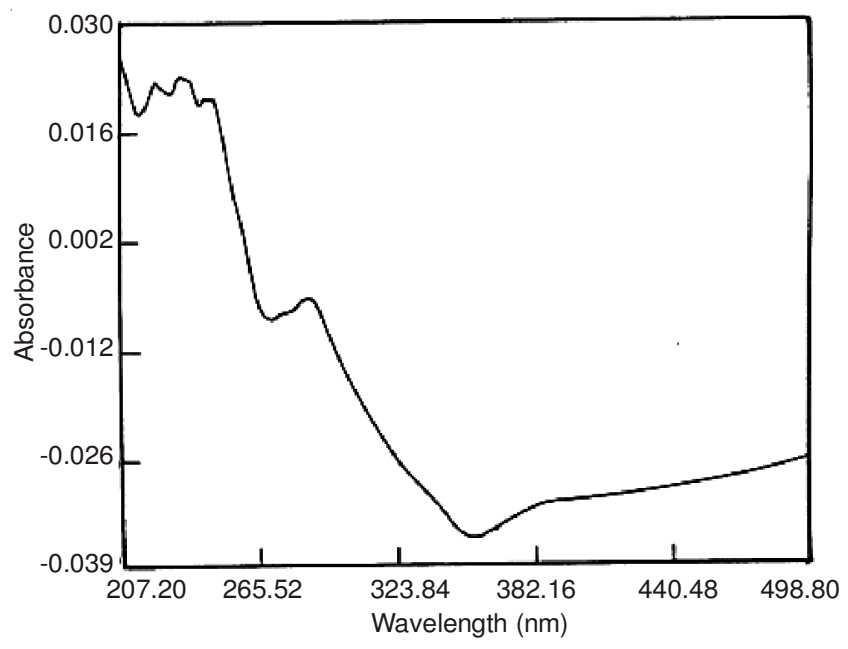

Fig.8. UV-visible spectrum of poly(3-chloroaniline)-blend-poly(vinyl alcohol) blend in DMSO exhibits band at $207 \mathrm{~nm}$ and $243 \mathrm{~nm}$. The absorption band at $207 \mathrm{~nm}$ is due to $\pi-\pi^{*}$ transition of the benzenoid and quinonoid rings and the band $245 \mathrm{~nm}$ is due to $\mathrm{n}-\pi^{*}$ transition. It occurs at longer wave length. When compared to polyaniline it is shifted to lower wave length because of the electronic effect which has reduced the amount of delocalization there by increasing the energy gap.

The TGA of the blend of poly(3-chloroaniline) and poly(vinyl alcohol) is given in Fig. 9. The sample decomposes in two steps. The initial loss of water takes place and then the sample decomposes continuously upto $535^{\circ} \mathrm{C}$. Even after $690{ }^{\circ} \mathrm{C}, 48.7 \%$ of the residue remains. This shows that the presence of chlorine has prevented the complete decomposition of the blend.

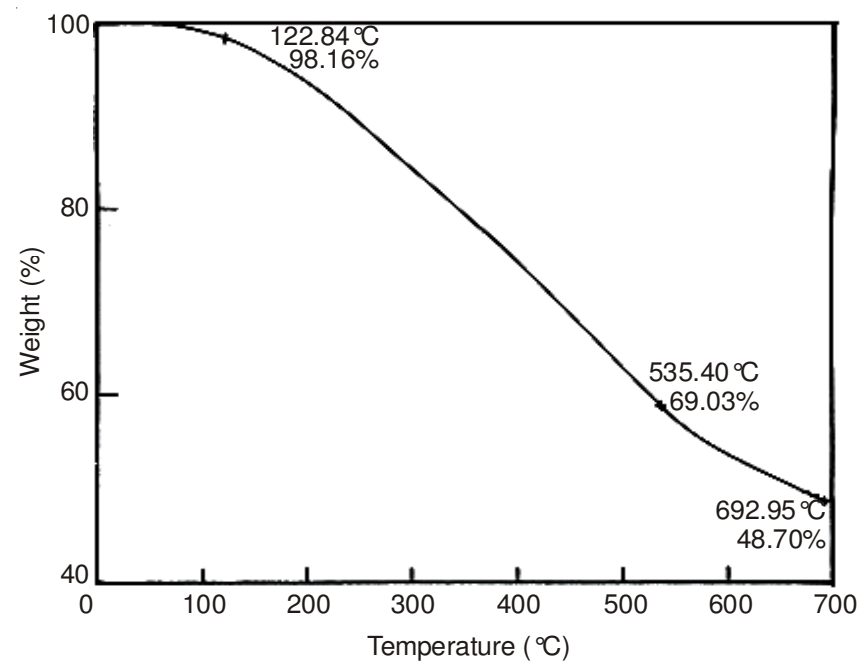

Fig. 9. TGA of blend of poly(3-chloroaniline)-blend-poly(vinyl alcohol)

Electrical conductivity studies: The polymer and its blends were finely powdered and pressed into a pellet using IR Sample Press using Model AVAPAR-330 Thermonicolate at a maximum pressure of $15 \mathrm{tons} / \mathrm{cm}^{2}$ to form a circular pellet of $12 \mathrm{~mm}$ diameter. The thickness of the pellet was measured using screw gauge. The measurement was done by placing the pellet between two silver electrodes and the bulk resistance $\left(R_{b}\right)$ was measured using computational analysis using HPVEE programmes and the values are tabulated in Tables-4-6.

\begin{tabular}{ccccc}
\multicolumn{5}{c}{ TABLE-4 } \\
\multicolumn{5}{c}{$\begin{array}{c}\text { COMPLEX IMPEDANCE MEASUREMENT } \\
\text { OF POLY(3-CHLORO ANILINE) }\end{array}$} \\
\hline $\begin{array}{c}\text { Frequency } \\
\text { in Hz }\end{array}$ & $\begin{array}{c}\text { Impedance } \\
\text { in ohm }\end{array}$ & $\theta$ in degree & $\mathrm{Z} \cos \theta$ & $-\mathrm{Z} \sin \theta$ \\
\hline 1000000 & 14709 & -89.28 & 186 & 14708 \\
320000 & 45120 & -89.17 & 651 & 45115 \\
100000 & 142847 & -89.02 & 2444 & 142826 \\
35294 & 400710 & -88.91 & 7621 & 400638 \\
8000 & 1738120 & -88.63 & 41447 & 1737626 \\
2000 & 6826300 & -88.02 & 235710 & 6822229 \\
500 & 26488900 & -87.46 & 1176214 & 26462773 \\
100 & 125655000 & -87.82 & 4771463 & 125564375 \\
20 & 731266000 & -90.72 & -9204432 & 731208070 \\
\hline
\end{tabular}

The plot gives $-Z \sin \theta$ vs. Z $\cos \theta$ as in Figs. 10-12. The point of intersection of the impedance plot on the real axis at 
TABLE-5

COMPLEX IMPEDANCE MEASUREMENT OF POLY(3CHLOROANILINE)-BLEND-POLYETHYLENEGLYCOL

\begin{tabular}{ccccc}
\hline $\begin{array}{c}\text { Frequency } \\
\text { in } \mathrm{Hz}\end{array}$ & $\begin{array}{c}\text { Impedance } \\
\text { in ohm }\end{array}$ & $\theta$ in degree & $\mathrm{Z} \cos \theta$ & $-\mathrm{Z} \sin \theta$ \\
\hline 1000000 & 52510 & -83.41 & 6029 & 52163 \\
320000 & 150115 & -84.53 & 14310 & 149431 \\
100000 & 451466 & -85.04 & 38997 & 449779 \\
35294 & 1211570 & -85.12 & 103152 & 1207171 \\
8000 & 4930390 & -84.94 & 434949 & 4911167 \\
2000 & 18446600 & -84.56 & 1749889 & 18363413 \\
500 & 67473400 & -84.11 & 6918659 & 67117746 \\
100 & $3.39 \mathrm{E}+08$ & -96.32 & $-3.7 \mathrm{E}+07$ & $3.37 \mathrm{E}+08$ \\
20 & $1.38 \mathrm{E}+09$ & -95.45 & $-1.3 \mathrm{E}+08$ & $1.37 \mathrm{E}+09$ \\
\hline
\end{tabular}

TABLE-6

COMPLEX IMPEDANCE MEASUREMENT OF POLY(3CHLOROANILINE)-BLEND-POLYVINYLALCOHOL

\begin{tabular}{ccccc}
\hline $\begin{array}{c}\text { Frequency } \\
\text { in Hz }\end{array}$ & $\begin{array}{c}\text { Impedance } \\
\text { in ohm }\end{array}$ & $\theta$ in degree & $\mathrm{Z} \cos \theta$ & $-\mathrm{Z} \sin \theta$ \\
\hline 1000000 & 63162 & -69.68 & 22009 & 59204 \\
320000 & 153779 & -70.41 & 51569 & 144875 \\
100000 & 384649 & -68.40 & 141597 & 357638 \\
35294 & 841475 & -65.24 & 352449 & 764107 \\
8000 & 2371810 & -59.91 & 1189116 & 2052191 \\
2000 & 5747700 & -55.38 & 3265538 & 4729939 \\
500 & 13488300 & -51.28 & 8437190 & 10523691 \\
100 & 33971000 & -36.73 & 27227905 & 20314282 \\
20 & 54610700 & -15.63 & 52590052 & 14717844 \\
\hline
\end{tabular}

the high frequency region within the frequency range under investigation gives the bulk resistance of the sample.

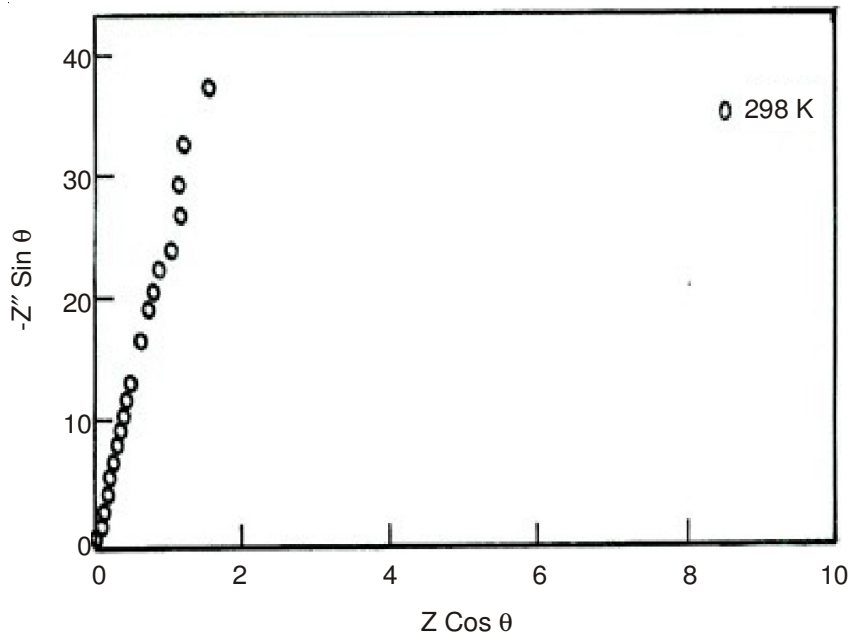

Fig. 10. Complex impedance plot of poly(3-chloroaniline)

The electrical conductivities of the poly(3-chloroaniline), poly(3-chloroaniline)-blend-polyethyleneglycol and poly(3chloroaniline)-blend-poly(vinyl alcohol) are calculated using the formula.

$$
\sigma=\frac{\mathrm{t}}{\mathrm{R} \times \mathrm{A}}
$$

where ' $\mathrm{t}$ ' is the thickness of the pellet, ' $\mathrm{A}$ ' is the area of the cross section and ' $\mathrm{R}$ ' is the bulk resistance of the individual sample.

The electrical conductivity of the blend of poly(3-chloroaniline) is

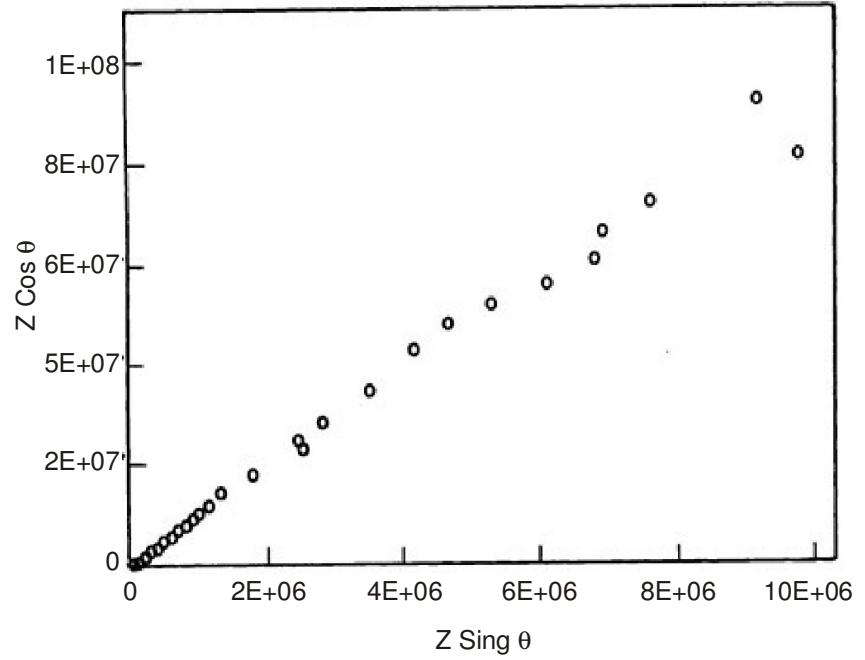

Fig. 11. Complex impedance plot of poly(3-chloroaniline)-blendpolyethyleneglycol

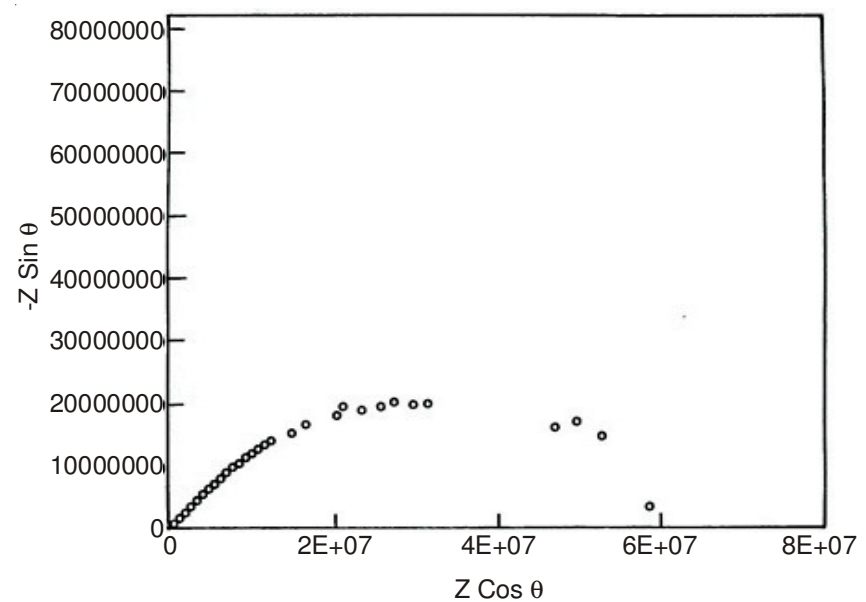

Fig. 12. Complex impedance plot of poly(3-chloroaniline)-blend-poly(vinyl alcohol)

$$
\begin{aligned}
\sigma= & 0.31 \times 10^{-1} / 1.7086 \times 10^{9} \times 1.3279 \\
= & 1.37 \times 10^{-11} \mathrm{~S} \mathrm{~cm}^{-1}
\end{aligned}
$$

The electrical conductivity of poly(3-chloroaniline)blend-polyethyleneglycol is

$$
\begin{aligned}
\sigma & =0.102 / 2.40 \times 10^{9} \times 1.1304 \\
& =3.67 \times 10^{-11} \mathrm{~S} \mathrm{~cm}^{-1}
\end{aligned}
$$

The electrical conductivity of poly(3-chloroaniline)blend-poly(vinyl alcohol) is

$$
\begin{aligned}
\sigma & =0.2 / 6.4 \times 10^{7} \times 1.1304 \\
& =2.64 \times 10^{-9} \mathrm{~S} \mathrm{~cm}^{-1}
\end{aligned}
$$

The electrical conductivities of the poly(3-chloroani line), poly(3-chloroaniline)-blend-polyethyleneglycol and poly(3-chloroaniline)-blend-poly(vinyl alcohol) are $1.37 \times 10^{-11}$ $\mathrm{S} \mathrm{cm}^{-1}, 3.67 \times 10^{-11} \mathrm{~S} \mathrm{~cm}^{-1}$ and $2.64 \times 10^{-9} \mathrm{~S} \mathrm{~cm}^{-1}$, respectively.

\section{Conclusion}

Poly(3-chloroaniline), poly(3-chloroaniline)-blendpolyethyleneglycol and poly(3-chloroaniline)-blendpoly(vinyl alcohol) have been successfully synthesized, characterized, thermal and electrical properties have been studied. The structure of the polymer and its blends consists of two types of rings, the quinonoid and benzenoid as shown by FTIR 
spectrum. The presence of $\mathrm{B}-\mathrm{N}^{+} \mathrm{H}-\mathrm{B} / \mathrm{Q}=\mathrm{N}^{+} \mathrm{H}-\mathrm{B}$ is supported by the presence of the peaks around $1140 \mathrm{~cm}^{-1}, 1114 \mathrm{~cm}^{-1}$ and $1124 \mathrm{~cm}^{-1}$ in the polymer and its blends with polyethyleneglycol and poly(vinyl alcohol) respectively. The $\lambda_{\max }$ values in UV-visible spectra were lower than that of polyaniline due to the presence of chlorine in the meta position which has decreased the $\pi$-electron delocalization. The TGA shows that the presence of chlorine has prevented the complete combustion of the blends.

The conductivities of the polymer and its blends as measured by four point probe method were

(1) Poly ( $m$-chloro aniline $)=1.37 \times 10^{-11} \mathrm{~S} \mathrm{~cm}^{-1}$

(2) $\operatorname{Poly}(3$-chloroaniline)-blend-polyethyleneglycol = $3.67 \times 10^{-11} \mathrm{~S} \mathrm{~cm}^{-1}$

(3) $\operatorname{Poly}(3$-chloroaniline $)$-blend-poly(vinyl alcohol $)=$ $2.64 \times 10^{-9} \mathrm{~S} \mathrm{~cm}^{-1}$

The blends synthesized were of semiconducting nature and poly(3-chloroaniline)-blend-poly(vinyl alcohol) has higher conductivity than poly(3-chloroaniline) and poly(3-chloroaniline)-blend-polyethyleneglycol. This piece of work provides scope for further research in the field of conducting substituted polyaniline blends.

\section{REFERENCES}

1. H. Shirakawa, E.J. Louis, A.G. MacDiarmid, C.K. Chiang and A.J. Heeger, J. Chem. Soc., Chem. Commun., 16, 578 (1977).

2. H. Shirakawa, Angew. Chem. Int. Ed., 40, 2575 (2001).

3. A.G. MacDiarmid, Angew. Chem. Int. Ed., 40, 2581 (2001).

4. A.J. Heeger, Angew. Chem. Int. Ed., 40, 2591 (2001).

5. G. Tourrillan and Skotheim TA, Handbook of Conducting Polymers; Marcel Dekker, New York, p. 293 (1986)

6. K.S. Ryu, K.M. Kim, N.G. Park, Y.J. Park and S.H. Chang, J. Power Sources, 103, 305 (2002).

7. S.K. Dhawan, N. Singh and S. Venkatachalam, Synth. Met., 125, 389 (2001).

8. P. Somani, A.B. Mandale and S. Radhakrishnan, Acta Mater., 48, 2859 (2000).
9. K.G. Conroy and C.B. Breslin, Electrochim. Acta., 48, 721 (2003).

10. E.P. Maziarz III, S.A. Lorenz, T.P. White and T.D. Wood, J. Am. Soc. Mass. Spectrom., 11, 659 (2000).

11. A. Mirmohseni and R. Solhjo, Eur. Polym. J., 39, 21 (2003).

12. M.S. Rahmanifar, M.F. Mousavi and M. Shamsipur, J. Power Sources, 110, 229 (2002).

13. M.A. Khan, C. Perruchot, S.P. Armes and D.P. Randall, J. Mater. Chem., 11, 2363 (2001).

14. Z. Jin, Y.X. Su and Y.X. Duan, Sens. Actuators B, 71, 118 (2000).

15. D. Nicolas-Debarnot and F. Poncin-Epaillard, Anal. Chim. Acta, 475, 1 (2003).

16. M.J. Burchell, M. Willis, S.P. Armes, M.A. Khan, M.J. Percy and C. Perruchot, Planet. Space Sci., 50, 1025 (2002).

17. M.R. Anderson, B.R. Mattes, H. Reiss and R.B. Kaner, Science, 252, 1412 (1991).

18. H.S.O. Chan, S.C. Ng, W.S. Sim, K.L. Tan and B.T.G. Tan, Macromolecules, 25, 6029 (1992).

19. J. Anand, S. Palaniappan and D.N. Sathyanarayana, Prog. Polym. Sci., 23, 993 (1998)

20. A. Pud, N. Ogurtsov, A. Korzhenko and G. Shapoval, Prog. Polym. Sci., 28, 1701(2003).

21. W.Y. Zheng, K. Levon, J. Laakso and J.E. Osterholm, Macromolecules, 27, 7754 (1994).

22. M.T. Nguyen, P. Kasai, J.L. Miller and A.Z. Diaz, Macromolecules, 27, 3625 (1994).

23. R.N. Mohammad, S.T. Soheil, S. Roya and A.E. Ali, Iran. Polym. J., 17, 1 (2008).

24. M. Ranger and M. Leclerc, Synth. Met., 84, 85(1997).

25. Y. Sahin, S. Perçin and G.Ö. Alsancak, J. Appl. Polym. Sci., 89, 1652 (2003).

26. S. Palaniappan, Eur. Polym. J., 33, 1735 (1997).

27. A.L. Sharma, V. Saxena, S. Annapoorni and B.D. Malhotra, J. Appl. Polym. Sci., 81, 1460 (2001).

28. U.S. Waware and S.S. Umare, React. Funct. Polym., 65, 343 (2005).

29. J. Tang, X. Jing, B. Wang and F. Wang, Synth. Met., 24, 231 (1998).

30. Y.H. Kim, C. Foster, J. Chiang and A.J. Heeger, Synth. Met., 25, 49 (1998).

31. M. Wan, Synth. Met., 31, 51 (1989).

32. H. Kuzmany and N.S. Sariciftci, Synth. Met., 18, 353 (1987).

33. A.P. Monkman, D. Bloor, G.C. Stevens and J.C.H. Stevens, J. Phys. D: Appl. Phys., 20, 1337 (1987). 